\title{
Material Fatigue Properties for Assessing Mechanical Components Weakened by Notches and Defects
}

\author{
B. Atzori ${ }^{1}$, G. Meneghetti ${ }^{1}$ and L. Susmel ${ }^{2}$ \\ ${ }^{1}$ Department of Mechanical Engineering - University of Padova \\ Via Venezia, 1 - 35131 Padova (Italy), \\ e-mail: bruno.atzori@unipd.it, giovanni.meneghetti@unipd.it \\ ${ }^{2}$ Department of Engineering - University of Ferrara \\ Via Saragat, 1 - 44100 Ferrara (Italy), e-mail: 1susmel@ing.unife.it
}

\begin{abstract}
This paper addresses the problem of the material fatigue properties estimation for assessing real mechanical components. These information are needed to apply the most modern methods capable of assessing components weakened by notches and defects, subjected to both uniaxial and multiaxial fatigue loadings. In particular, by using a large database of fatigue data, some practical rules are proposed to estimate the plain material fatigue limit (under uniaxial and torsional loadings) and the El Haddad's short crack constant.
\end{abstract}

\section{INTRODUCTION}

The complex geometries of real mechanical components often generate stress concentration phenomena, which have a strong influence on the fatigue behaviour of the material. During the last few years some new methods capable of estimating the fatigue limit in the presence of both notches and defects have been developed. In general, the application of these methods requires the fatigue limit, $\Delta \sigma_{0}$, the threshold value of the stress intensity factor, $\Delta \mathrm{K}_{\text {th }}$, and the El Haddad's short crack constant, $\mathrm{a}_{0}$. The El Haddad's $\mathrm{a}_{0}$ is a material property and it can be calculated as [1]:

$$
\mathrm{a}_{0}=\frac{1}{\pi}\left(\frac{\Delta \mathrm{K}_{\mathrm{th}}}{\Delta \sigma_{0}}\right)^{2}
$$

Recently, Atzori and Lazzarin [2] proposed a diagram capable of making explicit the bridging between the defect and the notch sensitivity when the analysed component is in fatigue limit conditions. The same authors [3] developed then their approach in order to extend it to finite size components by introducing an equivalent notch depth accounting for the shape factor commonly used in fracture mechanics problems.

By using the critical distance concept, Taylor [4] demonstrated that accurate fatigue limit estimations could be even done by using just the linear-elastic stress ahead of the crack tip together with a critical distance directly related to the El Haddad's $\mathrm{a}_{0}$. In particular, he showed that the stress to be compared to the fatigue limit could be 
estimated at a point (point method), or averaged along a line (line method) or, finally, averaged over a semi-circular area (area method). These methods demonstrated to be successful for all kind of notches as well as for defects [5].
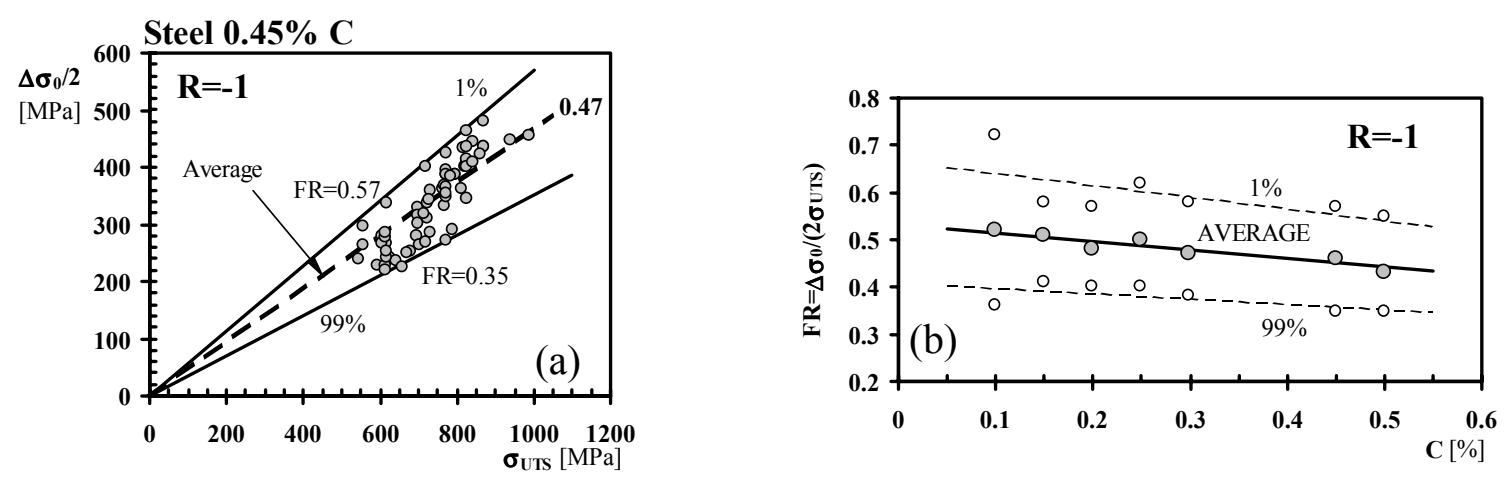

Figure 1. Relationship between fatigue strength at $10^{7}$ cycles to failure (assumed to be the reference fatigue limit) and tensile strength for carbon steels having $0.45 \%$ carbon content (a) and fatigue ratio vs. carbon content diagram (b) $[9,10]$.

Finally, by an extensive experimental investigation, Susmel and Taylor [6] suggested that both the Critical Distance Mechanics and the Susmel and Lazzarin multiaxial fatigue criterion [7] (reinterpreted in terms of the critical distance approach) could be successfully employed even for estimating the fatigue limit of sharply notched components subjected to in-phase biaxial loadings.

Aim of the present paper is to supply some practical rules allowing engineers engaged in fatigue assessment of real components to estimate the material fatigue properties to apply all the modern theories shortly mentioned above.

\section{ESTIMATION OF THE PLANE FATIGUE LIMIT}

Taking as starting point the classical diagram proposed by Fuchs [8], it has been firstly studied the relationship existing between the plain-specimen fatigue limit, $\Delta \sigma_{0}$, and the tensile stress, $\sigma_{\text {UTS }}$. By using the schematisation adopted in Ref. [9], metallic materials have been subdivided into five different groups: carbon steels, low-alloy steels, highalloy steels, aluminium alloys and cast irons.

Fatigue limits have been extrapolated at $10^{7}$ cycles to failure under the hypothesis of a log-normal distribution for each stress level with a confidence of $95 \%$. They have been always estimated at $10^{7}$ cycles to failure, even when there was a knee point positioned at a number of cycles lower than the assumed reference value. 

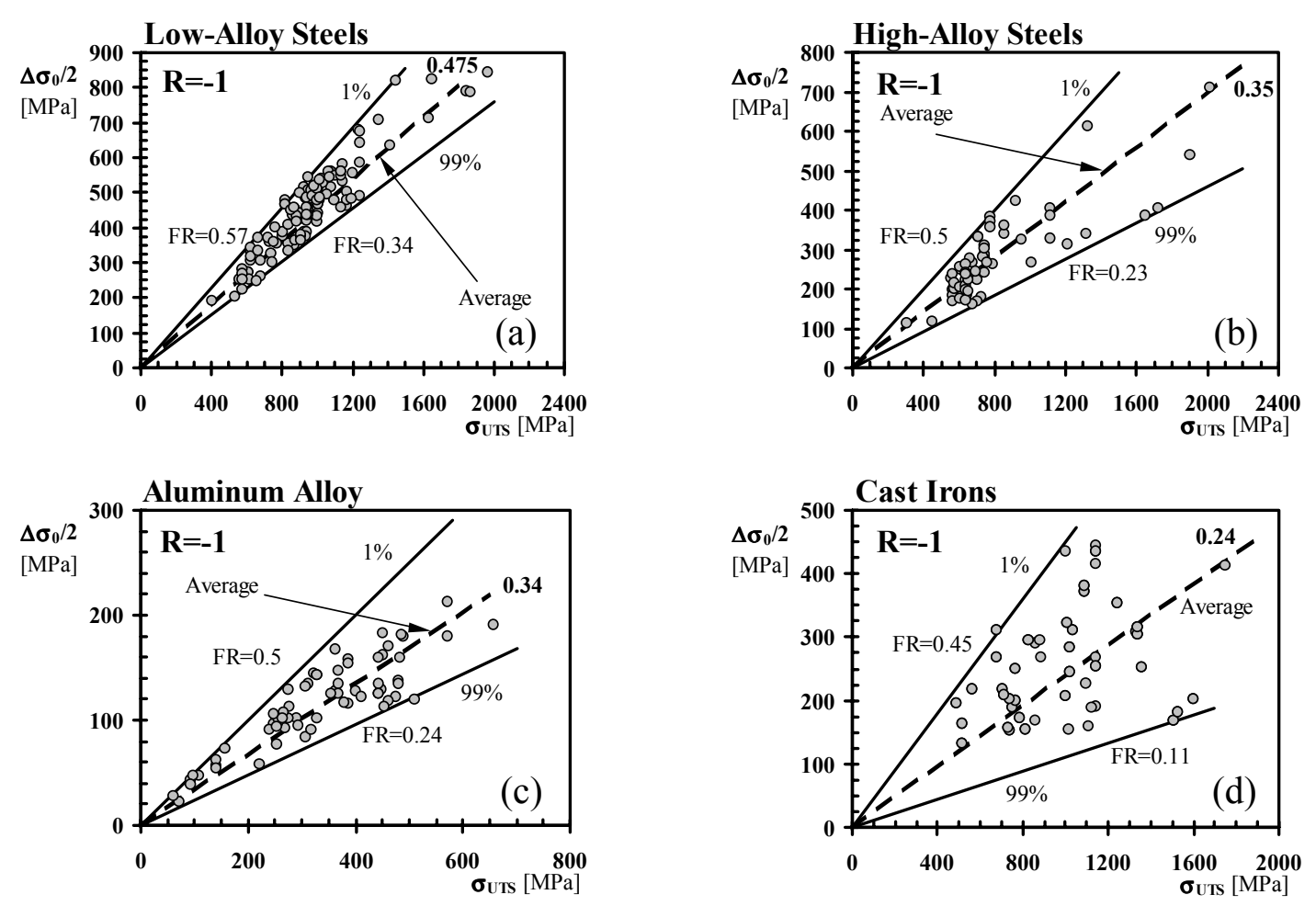

Figure 2. Relationship between fatigue strength at $10^{7}$ cycles to failure (assumed to be the reference fatigue limit) and tensile strength for low-alloy steels (a), high-alloy steels (b), aluminium alloy (c) and cast irons (d) [9-11].

In any case, a reference fatigue limit at $2 \cdot 10^{6}$ cycles could be estimated by using the following relationship:

$$
\Delta \sigma_{0,2 \cdot 10^{6}}=\Delta \sigma_{0,10^{7}} \cdot 5^{\frac{1}{\mathrm{k}}}
$$

where $\mathrm{k}$ is the Wöhler curve inverse slope ranging between 8 and 10 .

Moreover, all the collected data were generated under axial, bending, and rotating bending loadings. It is well known that the fatigue limit value depends on the load typology, but we reanalysed all the data together, because their statistical distribution was the same for every material class, independently of the applied loading type.

As an example, in Fig. 1a it has been reported the $\Delta \sigma_{0} / 2$ vs. $\sigma_{U T S}$ diagrams concerning steels having a carbon content of $0.45 \%$, whereas Fig. $1 \mathrm{~b}$ summarises all the performed re-analyses in terms of FR vs. carbon content, $\mathrm{C}$ [\%], relationships. The data re-analyses showed that the average value, calculated by using the least squares method, of the fatigue ratio (FR), where $\mathrm{FR}=\Delta \sigma_{0} /\left(2 \sigma_{\mathrm{UTS}}\right)$, decreases as the carbon content increases. In particular, FR reduces from 0.52 down to 0.43 , when the carbon content ranges from $0.1 \%$ up to $0.5 \%$. In Fg. $1 \mathrm{~b}$ it is possible to single out three different straight lines: the upper one interpolates the 1\% values of the determined FR, the one in between interpolates the average values of FR and the lower one its $99 \%$ values. These straight lines can be mathematically expressed as: 


$$
\begin{array}{ll}
1 \%: & \mathrm{FR}=-0.2511 \mathrm{C}[\%]+0.6685 \\
\text { Average: } & \mathrm{FR}=-0.183 \mathrm{C}[\%]+0.5338 \\
99 \%: & \mathrm{FR}=-0.1059 \mathrm{C}[\%]+0.4081
\end{array}
$$

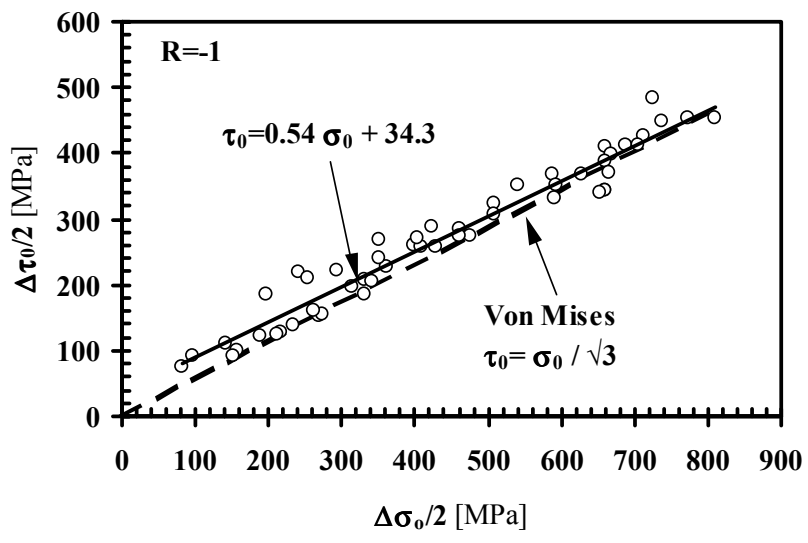

Figure 3. Relationship between the torsional and the uniaxial plane fatigue limit [12-30].
In Fig. 2 it has been performed the same analyses for low-alloy steels (Fig. 2a), high-alloy steels (Fig. 2b), aluminium alloys (Fig. 2c) and cast irons (Fig. 2d). The plotted diagrams show that the average value of the $\mathrm{FR}$ is equal to 0.475 for low-alloy steel, to 0.35 for high-alloy steels, to 0.34 for aluminium alloys and to 0.24 for cast-irons. Data concerning castirons are more spread than the others. This is a consequence of the strong influence on the FR value of the material microstructure [11].

More accurate relationships between $\Delta \sigma_{0}$ and $\sigma_{\text {UTS }}$ could be established by grouping together data generated by testing cast irons of the same typology.

Finally, in Fig. 3 it has been plotted the relationship between the uniaxial $\left(\Delta \sigma_{0} / 2\right)$ and the torsional plain fatigue limit $\left(\Delta \tau_{0} / 2\right)$. This figure shows that $\Delta \tau_{0} / 2$ can be always estimated conservatively by applying the Von Mises criterion.

\section{ESTIMATION OF THE THRESHOLD VALUE OF THE STRESS INTENSITY FACTOR}

It is common opinion [31] that the threshold value of the stress intensity factor, $\Delta \mathrm{K}_{\mathrm{th}}=\mathrm{K}_{1, \max }-\mathrm{K}_{1, \min }$, cannot be estimated by using just the ultimate stress. This idea is widely confirmed by Fig. $4 \mathrm{a}$, where the $\Delta \mathrm{K}_{\mathrm{th}} / \sigma_{\text {UTS }}$ vs. R diagram has been reported, being $\mathrm{R}=\sigma_{\min } / \sigma_{\max }$. This diagram shows that $\sigma_{\text {UTS }}$ does not allow the data to collapse into a restricted scatter band, and it holds true independently of the fatigue ratio value. Figure $4 \mathrm{a}$ has been built by using data generated by testing steels, but analogous situations have been found both for aluminium alloys and cast irons.

A different attempt to estimate $\Delta \mathrm{K}_{\text {th }}$ has been made by plotting $\Delta \mathrm{K}_{\text {th }}$ vs. the ratio $\Delta \sigma_{0} / \Delta K_{\text {th }}$ (Fig. $4 \mathrm{~b}$ ): this diagram allows us to single out different trends for the different considered materials. Even though this approach could supply approximate rules to estimate $\Delta \mathrm{K}_{\mathrm{th}}$, with the advantage of taking into account even the load ratio, estimations are still too poor. 

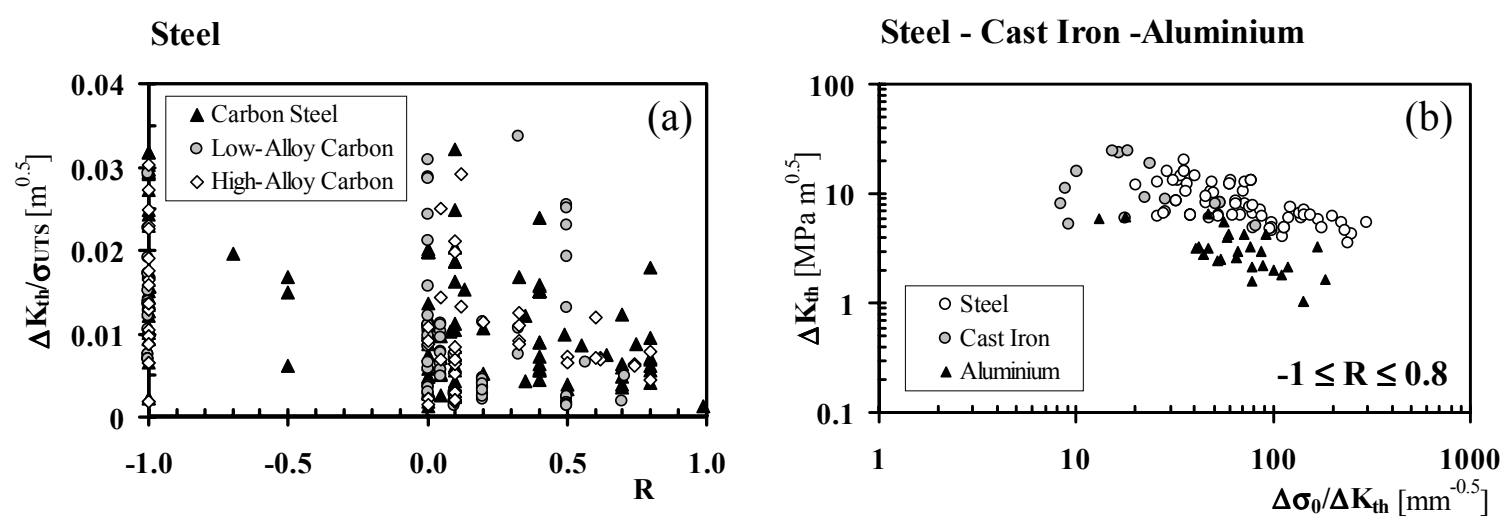

Figure 4. Relationship between $\Delta \mathrm{K}_{\mathrm{th}} / \sigma_{\mathrm{UTS}}$ and $\mathrm{R}$ for steels (a) [32]. Relationship between $\Delta K_{\text {th }}$ and $\sigma_{U T S} / \Delta K_{\text {th }}$ (b) [33-83].

\section{ESTIMATION OF THE EL HADDAD'S SHORT CRACK CONSTANT}

The El Haddad's short crack constant, given by Eq. (1), is one of the most important parameter on which all the new theory for assessing notched components are based [17]. This parameter is a material property that depends on the load ratio R. For this reason, it cannot be efficiently estimated by using the tensile stress, in fact, doing so, the $\mathrm{R}$ influence would not be taken into account. This problem can be partially overcome by expressing $\mathrm{a}_{0}$ as a function of the unnotched fatigue limit determined for the appropriate load ratio. In Fig. 5 it has been reported the $\mathrm{a}_{0}$ vs. $\mathrm{a}_{0} / \Delta \sigma_{0}$ diagrams for steels and cast irons (Fig. 5a) and for aluminium alloys (Fig. 5b). This figure shows that this schematisation allows all the data to collapse into two different restricted scatter bands, and it holds true independently of the load ratio value. Moreover, with only a small increase of the data scatter band (an increment of about $8 \%$ ), all the $a_{0}$ values can be summarised in an universal scatter band calculated by introducing the elastic strain determined, at the reference fatigue limit, as $\Delta \sigma_{0} / \mathrm{E}$, where $\mathrm{E}$ is the Young's modulus (Fig. 5c). The obtained trends can be also expressed in explicit form by using the mathematical relationships reported in Fig. 5.

\section{CONCLUSIONS}

In the present paper the problem of the material fatigue properties estimation has been addressed by using a large database of fatigue data. In particular, it has been proposed some practical rules capable of estimating the uniaxial and torsional plane fatigue limit and the El Haddad's short crack constant. 

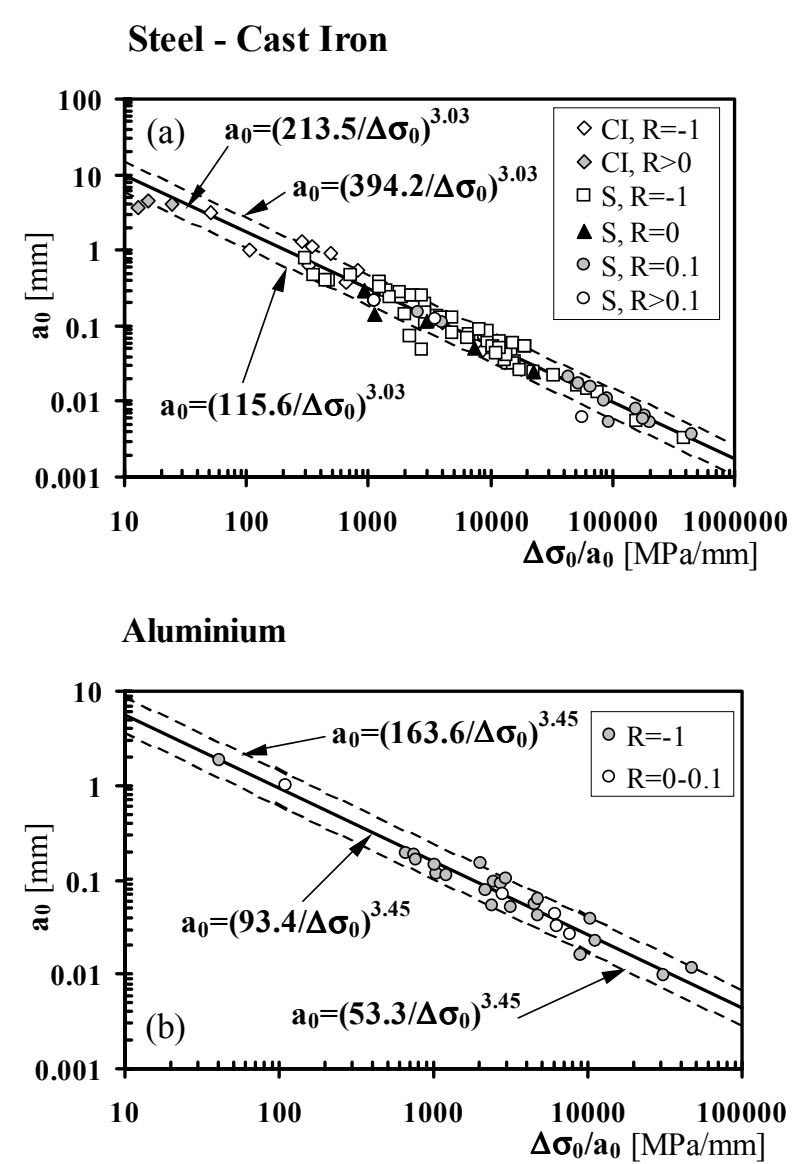

Steel - Cast Iron - Aluminium

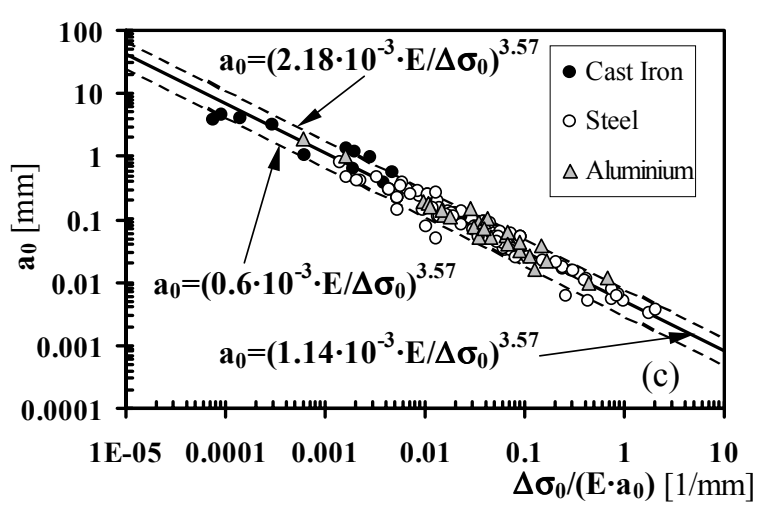

Figure 5. Relatiohship between $\mathrm{a}_{0}$ and $\Delta \sigma_{0} / \mathrm{a}_{0}$ for steel and cast-iron (a) and for aluminium alloy (b). Universal $\mathrm{a}_{0}$ vs. $\Delta \sigma_{0} /\left(\mathrm{Ea}_{0}\right)$ diagram (c).
Unfortunately, the available data did not allow us to propose any efficient rule capable of estimating the threshold value of the stress intensity factor, even if a synthesis diagram has been proposed.

Finally, it is important to highlight that, even though the proposed data re-analyses can represent an useful tool to perform a preliminary fatigue assessment, it is Author's opinion that these values are only engineering estimations. In fact, materials can show behaviours that could be affected by different parameters (like heat treatments, manufactory processes, etc.), which have not been systematically taken into account in the present study.

\section{REFERENCES}

1. El Haddad, M. H., Dowling, N. F., Topper T. H., Smith, K. N. (1980) Int. J. Fract. 16, 15-24.

2. Atzori, B., Lazzarin, P. (2000) Int. J. Fracture 107, L3-L8.

3. Atzori, B., Lazzarin, P., Meneghetti, G. (2003) Fatigue Fract. Engng. Mater. Struct. 26, 257-267.

4. Taylor, D. (1999) Int. J. Fatigue 21, 413-420.

5. Taylor, D., Wang, G. (2000) Fatigue Fract. Engng. Mater. Struct. 23, 387-394.

6. Susmel, L., Taylor, D. (2002) In: FATIGUE 2002, Blom, A. (Ed.), 1889-1897.

7. Susmel, L., Lazzarin, P. (2002) Fatigue Fract. Engng. Mater. Struct. 25, 63-78. 
8. Fuchs, H. O., Stephens, R. I. (1980) Metal Fatigue in Engineering, J. Wiley \& Sons

9. Anon. (1996) Data Book on fatigue strength of metallic materials, JSMS, Elsevier.

10. Boller, Chr., Seeger, T. (1987) Materials data for cyclic loading, Elsevier.

11. Gasparini, E., Meneghetti, G. (2002). La Metallurgia Iitaliana 3, 357-366.

12. Rotvel, F.(1970). Int. J. of Mech. Sc. 12, 597-615.

13. Nishihara, T., Kawamoto, M. (1945) Memoirs of the College of Engineering, Kyoto Imperial University 11, 85-112.

14. Achtelik, H., Jakubowska I., Macha, E. (1983) Studia Geot. et Mech. V 2, 9-30.

15. Zenner, H., Heidenreich, R., Richter, I. (1985) Z. Werkstofftech 16, 101-112.

16. Froustey, C., Laserre, S. (1989) Int. J. Fatigue 11, 169-175.

17. Simbürger, A. (1975) LBF Bericht Nr. FB-121, Darmstad, Germany.

18. Findley, W. N., Coleman, J. J., Hanley, B. C. (1956) In: Proc. Int. Conf. on Fatigue of Metals, Institution of Mechanical Engineers, London, 150-157.

19. Kurath, P., Downing, S. D., Galliart, D. R. (1989) In: Multiaxial Fatigue, SAE AE14, 13-32.

20. Laserre, S., Froustey, C. (1992) Int. J. of Fatigue 14, 113-120.

21. Palin-Luc, T., Lasserre, S. (1998) Eur. J. Mech. A/Solids 17, 237-251.

22. McDiarmid, D. L. (1985) In: Multiaxial Fatigue, ASTM STP 853, Miller, K. M. and Brown, M. W. (Ed.), 497-513.

23. Papadopoulos, I. V., (1995) Fatigue Fract. Engng. Mater. Struct. 18, 79-91.

24. Crossland, B. (1956) In: Proc. Int. Conf. on Fatigue of Metals, 138-149.

25. Issler, L. (1973). Dissertation, Universität Stuttgard.

26. Gough, H. J. (1949) In: Proc. Inst. Mech. Engrs. 160, 417-440.

27. McDiarmid, D. L. (1994) Fatigue Fract. Engng. Mater. Struct. 17, 1475-1484.

28. Kitaioka, S., Chen, J., Seika, M. (1986) Bulletin of JSME 29, 214-237.

29. Ros, M. (1950) EMPA Bericht 173, Zurich.

30. Frith, P. H. (1956) In: Int. Conf. Fatigue Inst. Mech. Engrs, 462-499.

31. Smith R. A. (1981) In: Fatigue Thresholds. Backlund, J. et al. (Ed.).

32. Taylor, D., Jianchum, L. (1993) Sourcebook on fatigue crack propagation, EMAS.

33. Frost, N. E. (1957) In: Proc. Inst. Mech. Engrs. 173, 811-834.

34. DuQuesnay, D. L. et al. (1986) In: The behaviour of short fatigue cracks, Miller, K. J. and De Los Rios, E. R. (Ed.), 323-335

35. Lukas, P. et al. (1986) Fatigue Fract. Engng Mater. Struct. 9, 195-204.

36. Tanaka, K., Nakai, Y. (1983) Fatigue Fract. Engng. Mater. Struct. 6, 315-327.

37. Taylor, D. Hughest, M., Allen, D. (1996) Int. J. Fatigue 18, 439-445.

38. Atzori, B., Meneghetti, G., Susmel, L. (2003) Eng. Frac. Mech., in press.

39. Nisitani, H., Endo, M. (1988) ASTM STP 924, 136-153.

40. Luise, M. (2001) Degree Thesis, Univ. of Padova.

41. Frost, N. E. (1957) Aeoronaut. Quart. VIII, 1-20.

42. El Haddad, M. H. (1978) Ph. D. Thesis, University of Waterloo, Waterloo, Ontario.

43. Gasparini E. (2001) Degree Thesis, Univ. of Padova.

44. Akiniwa, Y. et al. (2002) In: Proc. of FATIGUE 2002, Blom, A. (Ed.), 473-480.

45. Tokaji, K. et al. (1986) Fat. Fract. Engng. Mater. Struct. 9, 205-217.

46. Gach, E. et al. (2002) In: Proc. of FATIGUE 2002, Blom, A. (Ed.), 489-498.

47. Torres, Y. et al. (2002) In: Proc. oF FATIGUE 2002, Blom A. (Ed.), 1171-1177. 
48. Ochi, Y. et alt. (2002) In: Proc. of Fatigue 2002, Blom, A. (Ed.), 2657-2664.

49. Glodez, S. et alt. (2002) Int. J. of Fatigue 24, 1013-1020.

50. Shang, D. G. et al. (1998) Int. J. Fatigue 20, 683-687.

51. Ostash, O. P., Panasyuk, V. V. (2001) Int. J. Fatigue 23, 627-636.

52. Vasudevan, A. K. et al. (2001) Int. J. Fatigue 23, S39-S53.

53. Stanzl-Tschegg, S. E., Mayer, H. (2001) Int. J. Fatigue 23, S231-237.

54. Makkonen, M. (2001). Int. J. Fatigue 23, 395-402.

55. Beretta, S., Matteazzi, S. (1996) Int. J. Fatigue 18, 451-456.

56. Peters, J. O. et al. (2002) Eng. Fract. Mech. 69, 1425-1446.

57. Newman, J. C., et al. (1999) Int. J. Fatigue 21, 109-119.

58. Liaw, P. K. et al. (1997) Eng. Fract. Mech. 57, 85-105.

59. Yates, J. R. et al. (2002) Fat. Fract. Engng. Mater. Struct. 25, 667-676.

60. Fujimoto, Y. et al. (2001) Eng. Fract. Mech. 68, 455-473.

61. Lukas, P., Kunz, L. (1992) In: Short Cracks, ESIS 13, Miller, K. J. (Ed.), 265-275.

62. Usami, S., Shida, S. (1979) Fatigue Fract. Engng. Mater. Struct. 1, 471-481.

63. Weiss, B. et al. (1979) Fat. Eng. Mat. Struct. 2, 73-84.

64. Chua-Yau, C., Da-Xing, G. (1983) Fat. Eng. Mat. Struct. 6, 167-176.

65. Tanaka, K., Nakai, Y. (1983) Fat. Eng. Mat. Struct. 6, 315-327.

66. Clement, P. et al. (1984) Fat. Eng. Mat. Struct., 7, 251-265.

67. Shu, C. M. et al. (1985) Fat. Eng. Mat. Struct. 8, 193-208.

68. Tokaji, K. et al. (1986) Fat. Eng. Mat. Struct. 9, 1-14.

69. Legris, L. et al. (1981) In: Proc.of FATIGUE 81, Sherratt, F. et al. (Ed.), 97-105.

70. Ogura, K. et al. (1987) In: Current Research on Fatigue Cracks, Tanaka, T. et al. (Ed.), Elsevier Applied Scince, 67-91.

71. Tanaka, K. (1987) In: Current Research on Fatigue Cracks, Tanaka, T. et al. (Ed.), Elsevier Applied Scince, 93-117.

72. Usami, S. (1987) In: Current Research on Fatigue Cracks, Tanaka, T. et al. (Ed.), Elsevier Applied Scince, 119-147.

73. Blom, A. F. et al. (1986) In: The behaviour of short fatigue cracks, Miller, K. J. et al. (Ed.), 37-66.

74. Plumtree, A., Schafer, S. (1986) In: The behaviour of short fatigue cracks, Miller, K. J. et al. (Ed.), 215-227.

75. Nakai, Y., Ohji, K. (1992) In: Short Fatigue Cracks, Miller, K. J. (Ed.), 169-189.

76. Weiss, B. et al. (1992) In: Short Fatigue Cracks, Miller, K. J. (Ed.), 423-438.

77. Duggan, T. V. (1981) In: Fatigue thresholds, Backlund, J. et al. (Ed.), 809-826.

78. El Haddad, M. H., Miettinen, B. I. (1981) In: Fatigue thresholds, Backlund, J. et al. (Ed.), 827-844.

79. Harkegard, G. (1981) In: Fatigue thresholds, Backlund, J. et al. (Ed.), 827-844.

80. Kitagawa, H. (1981) In: Fatigue thresholds, Backlund, J. et al. (Ed.), 1051-1068.

81. Sedyuk, V. A. et al. (1997) In: Advances in fracture research, Karihaloo, B. L. et alt. (Ed.), 1629-1635.

82. Knott, J. F. Fatigue (1997) In: Advances in fracture research, Karihaloo, B. L. et alt. (Ed.), 1213-1224.

83. McEvily, A. J. (1996) In: ASM Handbook, Fatigue and Fracture 91, 134-152. 